\title{
Surgery was more effective than orthosis for hallux valgus
}

\author{
Torkki M, Malmivaara A, Seitsalo S, et al. Surgery vs orthosis vs watchful waiting for hallux valgus. A randomized control \\ trial.JAMA 2001 May 16;285:2474-80.
}

\section{QUESTION: In patients with hallux valgus, what are the effectiveness and cost of surgical, orthotic, and no treatment?}

\author{
Sources of funding: \\ Finnish Office for \\ Health Technology \\ Assessment; Finnish \\ Medical Foundation; \\ Scientific Foundation of \\ Jorvi Hospital; \\ Scientific Foundation of \\ Mehiläinen Hospital. \\ For correspondence: \\ Dr M. Torkki, \\ Department of \\ Orthopaedic Surgery \\ Helsinki University \\ Central Hospital, \\ Topeliuksenkatu 5 , \\ 00260 Helsinki, \\ Finland. Fax +1358 \\ 947187551.
}

Design

Randomised (allocation concealed*), blinded (outcome assessors), * controlled trial with 1 year of follow up.

\section{Setting}

4 hospitals in a health district in Finland.

\section{Patients}

211 patients who had a painful bunion with the hallux valgus angle $\leqslant 35^{\circ}$ and the intermetatarsal angle $\leqslant 15^{\circ}$. Exclusion criteria were previous bunion surgery, hallux rigidus, hallux limitus, rheumatoid arthritis, use of foot orthoses, pregnancy, or age $>60$ years. Baseline data were obtained for 209 patients (mean age 48 y, 92\% women). Follow up was $98 \%$ and $97 \%$ at 6 and 12 months, respectively.

\section{COMMENTARY}

Bunions range in severity from mild to severe anatomic deformity of the hallux valgus angle, intermetatarsal angle, and sesamoids. ${ }^{1}$ Shoe modification is the first treatment considered for people with symptomatic bunions. Adults with bunions of mild-tomoderate severity may be candidates for orthotic treatment or surgical correction.

In this carefully done trial, Torkki $e t a l$ have shown that chevron osteotomy resulted in less pain, better function, improved cosmesis, and fewer footwear difficulties during the 12 month study period than did orthosis or watchful waiting. The authors noted 1 infection, 1 fracture, 1 nerve injury, and 1 recurrence after 97 osteotomies (without fixation or lateral release) but no avascular necrosis

Custom orthotics should be considered for patients with symptomatic mild-tomoderate bunion deformity. Chevron osteotomy provides relief of symptoms in this population but should be avoided in patients with severe bunions or in those with marked pronation of the great toe, joint incongruity, or tight adductors. Kwire fixation may decrease the recurrence rate. Lateral release may cause avascular necrosis. ${ }^{2}$ Surgeons must carefully consider all abnormalities. Proximal osteotomy and soft tissue procedures may be required to correct the deformity.

Hans J Kreder, MD, MPH University of Toronto Toronto, Ontario, Canada

1 Mann R, Coughlin MJ. Adult hallux valgus. In: Mann RA, Coughlin MJ, eds. Surgery of the foot and ankle. Sixth edition. St. Louis: Mosby, 1993:167-296.

2 Coughlin MJ. Hallux valgus. J Bone Joint Surg Am 1996;78:932-66.

\section{Intervention}

Patients were allocated to surgery (chevron procedure) $(\mathrm{n}=71)$, foot orthosis (negative cast technique) $(\mathrm{n}=69)$, or watchful waiting (control) $(\mathrm{n}=69)$.

\section{Main outcome measures}

Duration of foot pain, foot pain intensity $(100 \mathrm{~mm}$ visual analog scale [VAS]: $0=$ no pain, $100=$ unbearable pain), ability to work (VAS: $0=$ inability to work, $100=$ maximum working ability), cosmetic disturbance (7 point scale: $0=$ no cosmetic disturbance, $6=$ maximum cosmetic disturbance), footwear problems (none to severe), functional status (American Orthopaedic Foot and Ankle Society score: 0 to 100 ; higher score $=$ better functional ability) (12 mo only), patient global assessment (12 mo only), and footcare costs.

\section{Main results}

At 6 months, patients who received surgery or orthoses had less foot pain than did patients who received no treatment. Surgery group patients had less cosmetic disturbance and fewer footwear problems than did patients who received either no treatment or orthoses. At 12 months, surgery group patients had fewer days with pain in the previous 6 months, less pain and cosmetic disturbance, better functional status, and fewer footwear problems $(p<0.01)$ than either of the other 2 groups (table). More surgery and orthosis group patients reported better global foot assessment than did patients who received no treatment $(\mathrm{p}<0.01)$. Mean costs related to foot care were higher in the surgery group than in the orthosis and control groups (US\$ 930, 221, and 125 , respectively, over $12 \mathrm{mo}$ ).

\section{Conclusion}

In patients with mild or moderate hallux valgus, surgery had greater long-term effectiveness than did orthotic treatment but was associated with greater costs.

*See glossary.

Surgery, foot orthosis, or watchful waiting (control) for hallux valgus at 12 months $†$

\begin{tabular}{|c|c|c|c|c|}
\hline \multirow[b]{2}{*}{ Outcomes } & & \multicolumn{2}{|c|}{ Difference in adjusted group mean $(95 \% \mathrm{Cl})$} & \\
\hline & & Surgery $v$ control & Surgery $v$ orthosis & \\
\hline \multicolumn{2}{|l|}{ Pain in past 6 months $(\mathrm{d})$} & 22 (1 to 42$)$ & 34 (14 to 55$)$ & \\
\hline \multicolumn{2}{|c|}{ Pain intensity (100 mm VAS) } & 19 (10 to 28$)$ & 14 (5 to 22$)$ & \\
\hline \multicolumn{2}{|c|}{ Cosmetic disturbance (7 point scale) } & $1.2(0.6$ to 1.8$)$ & $1.4(0.8$ to 2.1$)$ & \\
\hline \multicolumn{2}{|c|}{ AOFAS score $(0$ to 100$)$} & $11(7$ to 16$)$ & 11 (7 to 15$)$ & \\
\hline & Comparisons & Event rates & $\mathrm{RBI}(\mathrm{Cl})$ & NNT (Cl) \\
\hline \multirow[t]{2}{*}{ No footwear problems } & Surgery $v$ control & $35 \% \vee 7.5 \%$ & $386 \%(108$ to 1079$)$ & 4 (3 to 7$)$ \\
\hline & Surgery $v$ orthosis & $35 \% \vee 4.5 \%$ & $710 \%$ (179 to 2352$)$ & $4(3$ to 6$)$ \\
\hline
\end{tabular}

†AOFAS = American Orthopaedic Foot and Ankle Society; VAS = visual analog scale. Other abbreviations defined in glossary; RBI, NNT, and Cl calculated from data in article. 